
\title{
Variability Analysis and Forecasting of Relative Humidity in Bangladesh
}

\author{
J. A. Syeda \\ Department of Statistics, Hajee Mohammad Danesh Science and Technology University \\ Dinajpur, Bangladesh
}

\begin{abstract}
An attempt was made to investigate the trend and variability pattern for decadal, annual and seasonal (three crop seasons) average relative humidity (ARH) of six divisional stations in Bangladesh: Dhaka, Rajshahi, Khulna, Barisal, Sylhet and Chittagong. The rates of linear trend (LT) for minimum, maximum and range humidity were examined too. The monthly ARH for 2009-2012 were forecasted using the univariate Box-Jenkin's ARIMA (autoregressive integrated moving average) modelling technique. The rates of LT for annual ARH were found negative for Dhaka and Chittagong but positive for others. The rates were found negative for all the coefficient of variations (CVs). The rate for annual minimum humidity was positive for Dhaka but negative for others. The rates for annual maximum and range humidity were negative for Dhaka and Chittagong but positive for others. The rates for seasonal ARH were negative for Dhaka while positive for Rajshahi and Barisal in all the three seasons. It was negative for Kharif season, whereas positive for Prekharif and Rabi seasons for Khulna and Sylhet. It was negative for Kharif and Prekharif seasons, as the same time as positive for Rabi season for Chittagong.
\end{abstract}

Key wards: Forecasting, relative humidity, variability analysis

\section{Introduction}

Atmospheric water vapor is a complex meteorological element. It is a fundamental component in the climate system as the most significant greenhouse gas and a key driver of many atmospheric processes. Water vapor and its transport around the atmosphere is a fundamental component of the hydrological cycle. The vapor plays a key role in determining the dynamic and radiative properties of the climate system. Humidity is the amount of water vapor in the air, and relative humidity considers the ratio of the actual vapor pressure of the air to the saturated vapor pressure which is usually expressed in percentage. Humidity affects crops through evaporation, transpiration and condensation (Lenka, 1998). Crop agriculture is highly influenced by climatic change and majority of population is dependent on agricultural crop in Bangladesh. The prediction of atmospheric parameters is essential for climate monitoring, drought detection, severe weather prediction, agriculture and production, planning in energy and industry, communication, pollution dispersal etc. Accurate prediction of weather parameters is a difficult task due to the dynamic nature of the atmosphere. In this paper, the linear trends for annual and seasonal relative humidity (average, minimum, maximum and range) were examined and Box-Jenkin's ARIMA model was fitted for forecasting the monthly ARH from January 2009December 2012 for the six divisional stations.

\section{Sources of Data and Methodology}

\section{Sources of Data}

Data were taken from Bangladesh Meteorological Department, Dhaka. The monthly average, maximum and minimum relative humidity in percentage were taken for the six divisions: Dhaka, Rajshahi, Khulna, Barisal, Sylhet and Chittagong for 1953-2008, 19642008, 1948-2008, 1949-2008, 1956-2008 and 19492008, respectively. The missing data were filled in with the median for the corresponding years. The seasonal data for the three crop seasons: Prekharif (March to May), Kharif (June to October) and Rabi (November to February) were the averages of the monthly data taken from March to May, June to October and November to February A divisional map of Bangladesh is shown in Fig. 1.

\section{Methodologies}

In this section, the within and between-year variability for annual and seasonal ARH was calculated. The linear trend for annual and seasonal ARH was fitted with the least square method taking the following form of equation-

$Y=c+b X$

where, $Y$ is $A R H, X$ is time, $b$ is a fixed parameter to be estimated; it is the population average change in $\mathrm{Y}$ per one unit change in $\mathrm{X}$; and $c$ is a constant which is used to estimate the effect of excluded independent variable on the overall level of $\mathrm{Y}$. The linear trend for annual and seasonal minimum relative humidity (MNRH), maximum relative humidity (MXRH) and range relative humidity (RNRH) were also examined using the similar method. 




Fig. 1. A divisional map of Bangladesh

Stationarity of residuals for ARH trend was tested using the ACF (autocorrelation function) and the PACF (partial autocorrelation function) display and the normality was validated by normal probability plot. The value of classical ' $t$ ' test was used for the identification of significant ARH trend when residuals followed the normality pattern.

Univariate Box-Jenkin's ARIMA model was fitted to forecast the monthly ARH data for January 2009December 2012. After confirming that the series was stationary, an effort was made for an ARIMA model to express each observation as a linear function of the previous value of the series (autoregressive parameter) and of the past error effect (moving average parameter). The available data were divided into training, validation and test sets. The training set was used to build the model, the validation set is used for parameter optimization and the test set was used to evaluate the model. The adequacy of the above model was checked by comparing the observed data with the forecasted results. Data from the last ten years were used to compare with the fitted model forecasts for the years and the models were selected for the minimum root mean square forecasting error of the data set of those ten years. The diagnostic techniques namely histogram of residuals, normal probability plot of residuals, ACF and PACF display of residuals, TS (time series) plots for residual versus fitted values and TS plots for residual versus order of the data were used for checking residuals of ARIMA models. Box-Cox transformation is used for variance stabilization and the transformation of the data to get stationary series from nonstationary series (Pankraiz, 1991). The software package 'Minitab 13' was used to fit the ARIMA univariate models.

Box Jenkins Modelling Strategy and ARIMA Model Box and Jenkins (1976) formalized the ARIMA modeling framework in the three steps: (I) Identification, (II) Estimation and (III) Verification. In the identification stage, the objective was to identify that how many terms to be included was based on the autocorrelation function (ACF) and partial autocorrelation function (PACF) of the differenced and/or transformed time series (Box and Jenkins, 1976). In the estimation stage, the coefficients of the model were estimated by the maximum likelihood method. The verification of the model was performed through diagnostic verification of the residuals (histogram or normal probability plot of residuals, standardized residuals and ACF and PACF of the residuals). The performance of the ARIMA models was often tested through comparison of prediction with observation not used in the fitted model. An appropriate ARIMA model provides minimum mean squared error forecasts among all linear univariate models with fixed coefficients. It may produce point forecasts for each time period and interval forecasts constructing a confidence interval around each point forecast. To have the $95 \%$ interval for each forecast the formulae $f \pm 2 s$ was used where $f$ denotes a forecast and $s$ is its standard error. The forecasts for a stationary model converge to the mean of the series and the speed of converging movement depends on the nature of the model. For nonstationary model the forecasts do not converge to the mean. A detailed description of the nonseasonal and seasonal ARIMA models and the standardized notation used was provided in the following.

\section{Standardized ARIMA Notation}

ARIMA models have a general form of $p, d$, $q$ where $p$ is the order of standard autoregressive term AR, $q$ is the order of the standard moving average term MA and $\mathrm{d}$ is the order of difference. AR describes how a variable $\mathrm{y}_{\mathrm{t}}$ such as relative humidity depends on some previous values $\mathrm{y}_{\mathrm{t}-1}, \mathrm{y}_{\mathrm{t}-2}$ etc. whereas MA describes how this variable $y_{t}$ depends on a weighted moving

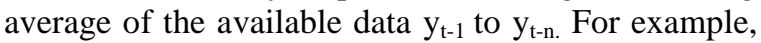
for a one step ahead forecast (say, for $\mathrm{t}$ being September) with an AR-1, all weight was given to the 
relative humidity in the previous month (September), while with an AR-2 the weight was given to the relative humidity of the two immediately previous months (September and August). By contrast, with a MA-1, MA-2, a certain weight is given to the relative humidity of the immediately previous month (September), a smaller weight was given to the relative humidity observed two months ago (August) and so forth, i.e., the weights decline exponentially.

The combined multiplicative seasonal ARIMA (p, d, q) $\times 12(\mathrm{P}, \mathrm{D}, \mathrm{Q})$ model can be described as the following:

$$
\phi_{p}(B) \Phi_{p}\left(B^{s}\right) \nabla_{s}^{D} \nabla^{d} z_{t}=C+\theta_{q}(B) \Theta_{Q}\left(B^{s}\right) \varepsilon_{t}
$$

In the standard expression of ARIMA model where $B$ denotes the backward shift operator where

- $\phi_{p}(B)=1-\phi_{1} B-\phi_{2} B^{2}-\ldots-\phi_{p} B^{p}$

The standard autoregressive operator of order $\mathrm{p}$ $-\Phi_{p}\left(B^{s}\right)=1-\Phi_{1} B-\Phi_{2} B^{2}-\ldots-\Phi_{p} B^{p s}$

For the seasonal autoregressive operator of order $p$

$-\nabla_{s}^{D}$ is the seasonal differencing operator of order $\mathrm{D}$

$-\nabla^{d}$ is the differencing operator of order $\mathrm{d}$

And $-y_{\mathrm{t}}$ is the value of the variable of interest at time $\mathrm{t}$

- $C=\mu \phi_{p}(B) \Phi_{p}\left(B^{s}\right)$ is a constant term, where $\mu$

is the true mean of the stationary time series being modeled. It was estimated from sample data using the approximate likelihood estimator approach.

- $\theta_{q}(B)=1-\theta_{1} B-\theta_{2} B^{2}-\ldots-\theta_{q} B^{q}$

The standard moving average operator of order $\mathrm{q}$ is:

- $\Theta_{Q}\left(B^{s}\right)=1-\Theta_{1} B^{1}-\Theta_{2} B^{2}-\ldots-\Theta_{Q} B^{Q S}$

The seasonal moving average operator of order $\mathrm{Q}$ is: $-\phi_{1}, \phi_{2}, \ldots . ., \phi_{p} ; \Phi_{1}, \Phi_{2}, \ldots, \Phi_{p} ; \theta_{1}, \theta_{2}, \ldots, \theta_{q}$; $\Theta_{1} \Theta_{2}, \ldots, \Theta_{Q}$ are unknown coefficients that were estimated from sample data using the approximate likelihood estimator approach. $-\varepsilon_{\mathrm{t}}$ is the error term at time at time $\mathrm{t}$, and

$-\mathrm{S}$ is the annual period of 12 months

Thus, the multiplicative seasonal modeling approach which has a general form of ARIMA (p, d, q) $\times S(P$, $\mathrm{D}, \mathrm{Q})$ has been used in this paper. In this form, $\mathrm{p}$ is order of the seasonal autoregressive term (ARS), Q is order of the seasonal moving average term, D is the order of the seasonal differencing and $\mathrm{s}$ is the annual cycle (e.g, s = 12 using the monthly data). ARS describes how variable y depends on $\mathrm{y}_{\mathrm{t}-12}$ (ARS-1), $\mathrm{y}_{\mathrm{t}}$. ${ }_{24}$ (ARS-2), etc., while MAS describes how y depends on a weighted moving average of the available data $\mathrm{y}_{\mathrm{t}-12}$ to $\mathrm{y}_{\mathrm{t}-12 \mathrm{n}}$. For example, for a one step ahead forecast (say, for $\mathrm{t}$ being September and with an ARS-1, all weight is given to the relative humidity in the previous September while with an ARS-2, the weight is given to the September relative humidity 1 and 2 years ago. By contrast, with a MAS-1, MAS-2, the model gives a certain weight to September relative humidity 1 year ago, to the September relative humidity 2 years ago, and so on. These weights decline exponentially.

\section{Results and Discussions}

\section{Within-Year Variability for ARH}

The within-year variability for annual and seasonal ARH for the six stations are presented in Table 1. Annual average ARH was highest (81.8) for Barisal and lowest (75.3) in Dhaka. Annual MXRH was top (85.3) in Barisal and smallest (79.2) for Dhaka too. Annual MNRH was uppermost (73.9) in Sylhet and least (70.4) for Rajshahi.

The seasonal Average ARH was peak in Kharif season for all stations but the least in Prekharif season for Dhaka, Rajshahi, Khulna and Barisal. For Sylhet and Chittagong, the lowest average ARH was in Rabi season. The CV was largest in Prekharif season and smallest in Kharif season for all stations except Barisal. For Barisal, the utmost CV was in Rabi season and minimum in Kharif season.

Table 1 Within-Year Variability for Annual and Seasonal ARH for Six Stations

\begin{tabular}{|c|c|c|c|c|c|c|c|c|c|c|c|c|c|c|c|c|c|c|c|c|}
\hline \multirow{2}{*}{ Period } & \multicolumn{3}{|c|}{ Dhaka } & \multicolumn{4}{|c|}{ Khulna } & \multicolumn{3}{|c|}{ Rajshahi } & \multicolumn{4}{|c|}{ Barisal } & \multicolumn{3}{|c|}{ Sylhet } & \multicolumn{3}{|c|}{ Chittagong } \\
\hline & Max & Ave & Min $C V$ & Max & Ave & Min & $\mathrm{CV}$ & Max Ave & Min & $\mathrm{CV}$ & Max & Ave & Min & $\mathrm{CV}$ & Max & Ave 1 & Min CV & Max & Ave Min & $\mathrm{CV}$ \\
\hline Annual & 79.2 & 75.3 & \begin{tabular}{|l|l|}
71.4 & 2.0 \\
\end{tabular} & 83.8 & 79.1 & 72.4 & 2.8 & \begin{tabular}{|l|l|}
80.7 & 75.9 \\
\end{tabular} & 70.4 & 3.7 & 85.3 & 81.8 & 73.3 & 2.9 & 80.8 & 78.27 & \begin{tabular}{|l|l|}
73.9 & 2.0 \\
\end{tabular} & 82.8 & \begin{tabular}{ll|l|}
79.1 & 73.7 \\
\end{tabular} & 2. \\
\hline Kharif & 87.8 & 0.0 & \begin{tabular}{|l|l|}
78.8 & 2.4 \\
\end{tabular} & 91.0 & 85.7 & 71.4 & 3.0 & \begin{tabular}{|l|l|}
87.2 & 84.2 \\
\end{tabular} & 79.8 & 2.0 & 89.8 & 87.3 & 82.0 & 1.8 & 88.0 & 85.78 & \begin{tabular}{|l|l|}
81.6 & 1.6 \\
\end{tabular} & 91.0 & 84.578 .2 & 2. \\
\hline Prekharif & 77.0 & 69.5 & \begin{tabular}{|l|l|}
64.0 & 4.3 \\
\end{tabular} & 82.0 & 74.1 & 64.7 & 5.1 & \begin{tabular}{ll|l|}
75.7 & 64.9 \\
\end{tabular} & 50.7 & 8.4 & 82.7 & 77.5 & 67.7 & 4.1 & 80.3 & 73.66 & \begin{tabular}{|l|l|}
63.3 & 4.4 \\
\end{tabular} & 82.3 & 76.870 .0 & 3. \\
\hline & 74.3 & 50 & \begin{tabular}{ll|l}
66.5 & 2.7
\end{tabular} & 80.5 & 74.7 & 64.8 & 4.8 & \begin{tabular}{l|l}
79.373 .7 \\
\end{tabular} & 64.8 & 5.3 & 85.5 & 78.16 & 66.0 & & 79.8 & 72. & \begin{tabular}{|l|l|}
60.0 & 4.2 \\
\end{tabular} & 79.0 & $|74.169 .5|$ & 53. \\
\hline
\end{tabular}




\section{Between-Year Variability}

\section{Annual and Seasonal ARH}

Table 2 presents the rates obtained from linear trend (LT) for annual and seasonal ARH with its residual's stationarity and normality. The rate of growth of annual ARH was negative for Dhaka $\left(-0.055^{*}\right)$ and Chittagong (-0.0299) while for other stations it was positive. The fairly high negative rates were for Khulna (- 0.144), Rajshahi (- 0.0554) and Barisal where the residuals were nononormal for Khulna but nonstationary for Barisal. The less negative rates were for Sylhet (- 0.0181) and Chittagong (- 0.0108) with normal and stationary residuals.

During Kharif season, the highly significant negative growth rates were for Dhaka $(-0.093 *)$ The fairly high negative rates were for Sylhet $(-0.0204)$ and Chittagong(- 0.0501) where the residuals were nonstationary for Chittagong. The less negative rate were for Khulna $(-0.0127)$ with the nonnormal residual. The significant positive rates were for Rajshahi (+0.068*) and Barisal (+ 0.095*).
During Prekharif season the fairly high negative rates were for Dhaka (-0.025) and significant negative rates were for Chittagong $\left(-0.039^{*}\right)$. The significant positive rates were for Rajshahi $\left(+0.260^{*}\right)$, Khulna $\left(+0.0571^{*}\right)$ and Barisal $\left(+0.095^{*}\right)$ and the fairly high positive rates were for Sylhet $(+0.046)$.

During Rabi season, the less negative rates were for Dhaka (-0.0048) and the less positive rates were for Chittagong. The fairly high positive rates were for rest of the four stations namely Rajshahi $(+0.213)$, Khulna (+ 0.112), Barisal $(+0.153)$ and Sylhet $(+$ 0.0871 ) where the residuals were nonnormal and/ or nonstationary.

The rate of growth of seasonal ARH was negative for Dhaka and positive for Rajshahi and Barisal in all the three seasons. It was negative during Kharif season and positive in Prekharif and Rabi seasons for Khulna and Sylhet. It was negative during Kharif and Prekharif season and positive in Rabi season for Chittagong.

Table 2 Rates Obtained from LT for Annual and Seasonal ARH and Residual's Stationarity and Normality

\begin{tabular}{|c|c|c|c|c|}
\hline Station & Annual & Kharif & Prekharif & Rabi \\
\hline Dhaka & $\begin{array}{l}-0.055^{*}(\mathrm{t}=-4.88, A p . \mathrm{N}, \\
\mathrm{S})\end{array}$ & $\begin{array}{l}-0.093 *(\mathrm{t}=-9.31, \mathrm{~N}, \\
\mathrm{S})\end{array}$ & $-0.025(\mathrm{t}=-1.00, \mathrm{~N}, \mathrm{~S})$ & $\begin{array}{l}-0.0048(\mathrm{t}=-0.32, \text { Ap. } \mathrm{N}, \\
\text { Ap.S })\end{array}$ \\
\hline Rajshahi & $+0.167 *(t=7.94, N, S)$ & $+0.068 *(\mathrm{t}=4.20, \mathrm{~N}, \mathrm{~S})$ & $+0.260 *(\mathrm{t}=5.32, \mathrm{~N}, \mathrm{~S})$ & $+0.213(\mathrm{t}=6.82, \mathrm{~N}, \mathrm{NS})$ \\
\hline Khulna & $+0.053(\mathrm{t}=3.43, \mathrm{NN}, \mathrm{NS})$ & $\begin{array}{l}-0.0127(\mathrm{t}=-0.07, \mathrm{NN}, \\
\mathrm{S})\end{array}$ & $+0.0571 *(\mathrm{t}=2.12, \mathrm{~N}, \mathrm{~S})$ & $+0.112(\mathrm{t}=5.20, \mathrm{NN}, \mathrm{NS})$ \\
\hline Barisal & + & $\begin{array}{l}+0.0505^{*} \\
(\mathrm{t}=5.14, \text { Ap.N, } \mathrm{S})\end{array}$ & $\begin{array}{l}+0.095^{*}(\mathrm{t}=4.66, \text { Ap. } \mathrm{N}, \\
\mathrm{S})\end{array}$ & $+0.153(\mathrm{t}=7.81, \mathrm{~N}, \mathrm{NS})$ \\
\hline Sylhet & $+0.0318(\mathrm{t}=2.25, \mathrm{NN}, \mathrm{NS})$ & $\begin{array}{l}-0.0204(\mathrm{t}=-1.73, \mathrm{~N}, \\
\mathrm{S})\end{array}$ & $+0.046(\mathrm{t}=1.60, \mathrm{~N}, \mathrm{~S})$ & $+0.0871(\mathrm{t}=3.49, \mathrm{NN}, \mathrm{S})$ \\
\hline Chittagong & $-0.0299(\mathrm{t}=-2.45, \mathrm{~N}, \mathrm{NS})$ & $\begin{array}{l}-0.0501(\mathrm{t}=- \\
.80, A p . N, N S)\end{array}$ & $-0.039 *(\mathrm{t}=-2.10, \mathrm{~N}, \mathrm{~S})$ & $+0.0035(\mathrm{t}=0.21$, Ap. N, NS $)$ \\
\hline
\end{tabular}

*Significant at 5\% level, S-stationary, NS-nonstationary, NN-nonnormal, Ap.N-approximately normal, Ap.Sapproximately stationary.

**Normality is a very important issue in almost all branches of statistical inference. The normality was checked by normal probability plot. In the normal probability plot, plotting the normalized ordered residuals were plotted against their expected values assuming normal distribution.

***Time series possessed non-constant mean and non-constant variance and the probability distribution of the data series comes from various distributions. Stationarity and nonstationarity test on time series data are important for observing the nature of the data and the validity of analysis. 
CV of Annual and Seasonal ARH

Table 3 presents the rates obtained from linear trend for $\mathrm{CV}$ of annual and seasonal ARH with its residual's stationarity and normality. The rates of $\mathrm{CV}$ of annual ARH were negative for all the six stations. Among these, significant negative rate was for Dhaka (0.056*), Rajshahi $\left(-0.159^{*}\right)$ and Barisal $\left(-0.059^{*}\right)$. The fairly high negative rates were for Khulna (-
0.074), Sylhet (- 0.108) and Chittagong (- 0.015) nonnormal and nonstationary residual. The rates of $\mathrm{CV}$ of ARH were negative for all the three seasons for Dhaka, Rajshahi, Khulna and Barisal. For Sylhet, the positive rate was for Kharif season and the negative rates were for Prekharif and Rabi season while the opposite direction was for Chittagong.

Table 3 Rates Obtained from LT for CV of Annual and Seasonal ARH and Residual's Stationarity and Normality

\begin{tabular}{|l|l|l|l|l|}
\hline Station & \multicolumn{1}{|c|}{ Annual } & \multicolumn{1}{c|}{ Kharif } & \multicolumn{1}{c|}{ Prekharif } & \multicolumn{1}{c|}{ Rabi } \\
\hline Dhaka & $-0.056^{*}(\mathrm{t}=-4.02, \mathrm{~N}, \mathrm{~S})$ & $-0.006(\mathrm{t}=-0.51, \mathrm{NN}, \mathrm{S})$ & $\begin{array}{l}-0.076^{*}(\mathrm{t}=-2.11, \mathrm{Ap} . \mathrm{N}, \\
\mathrm{S})\end{array}$ & $-0.024(\mathrm{t}=-1.08, \mathrm{~N}, \mathrm{~S})$ \\
\hline Rajshahi & $-0.159^{*}(\mathrm{t}=-6.01, \mathrm{~N}, \mathrm{~S})$ & $-0.051^{*}(\mathrm{t}=-3.07, \mathrm{~N}, \mathrm{~S})$ & $-0.115(\mathrm{t}=-1.68, \mathrm{~N}, \mathrm{~S})$ & $-0.098^{*}(\mathrm{t}=-3.92, \mathrm{Ap} . \mathrm{N}$, \\
$\mathrm{S})$
\end{tabular}

*Significant at 5\% level, S-stationary, NS-nonstationary, NN-nonnormal, Ap.N-approximately normal, Ap.S-

approximately stationary.

\section{Annual and Seasonal MNRH}

Table 4 presents the rates of LT for Annual and Seasonal minimum relative humidity $(\mathrm{MNRH})$ and their residual's stationarity and normality. The rate of growth of annual MNRH was found positive for Dhaka $(-0.047 *)$ while for other stations it was negative. The fairly high negative rates were for Khulna (- 0.144), Rajshahi (- 0.0554) and Barisal where the residuals were nononormal for Khulna but nonstationary for Barisal. The less negative rates were for Sylhet (- 0.0181) and Chittagong (- 0.0108) with normal and stationary residuals.

During Kharif season, the growth rates of MNRH were negative in all the six stations. The relatively higher negative rates were for Khulna (- 0.144), Dhaka (+ 0.0482), Barisal and Sylhet where the residuals were nononormal and lower for Rajshahi ($0.0554)$ and Chittagong (+ 0.0362). The residuals were nonstationary for Dhaka only.
During Prekharif season, the rates of LT for MNRH were positive for Dhaka $\left(+0.145^{*}\right)$, Rajshahi (+ $\left.0.0443^{*}\right)$, Barisal $(+0.0300)$ and Sylhet $(+0.0550)$ but negative for Khulna (- 0.0633) and Chittagong ($0.0284)$. The residuals were normal and stationary for all cases.

During Rabi season, the growth rates of MRH were found positive for Dhaka (+ 0.0482), Sylhet (+ $0.0233)$ and Chittagong $(+0.0362)$ while negative for (Rajshahi $\left.-0.155^{*}\right)$ Khulna (- 0.160*) and Barisal (0.0943). The residuals were nonstationary for Dhaka only.

The rate of growth of MNRH was negative during Kharif season and positive during Prekharif and Rabi season for Dhaka and Sylhet. It was negative during Kharif and Rabi season and positive in Prekharif season for Rajshahi and Barisal. It was negative during Kharif and Prekharif season but positive in Rabi season for Chittagong and it was negative in all the three seasons for Khulna. 
Table 4 Rates Obtained from LT for Annual and Seasonal MNRH and Residual's Stationarity and Normality

\begin{tabular}{|c|c|c|c|c|}
\hline Station & Annual & Kharif & Prekharif & Rabi \\
\hline Dhaka & $\begin{array}{l}+0.0111(t=0.46 \\
\text { Ap.N, NS) }\end{array}$ & $-0.0981 *(\mathrm{t}=-3.35, \mathrm{~N}, \mathrm{~S})$ & $+0.145^{*}(\mathrm{t}=3.09, \mathrm{~N}, \mathrm{~S})$ & $\begin{array}{l}+0.0482(\mathrm{t}=1.93, \\
\mathrm{N}, \mathrm{NS})\end{array}$ \\
\hline Rajshahi & $\begin{array}{l}-0.0554(\mathrm{t}=-1.22 \text {, } \\
\text { Ap.N,S ) }\end{array}$ & $\begin{array}{l}-0.0353(t=-0.46, \\
N N, S)\end{array}$ & $\begin{array}{l}+0.0443 *(t=11.02, \\
\text { Ap.N, S })\end{array}$ & $\begin{array}{l}-0.155^{*}(\mathrm{t}=-2.84, \\
\mathrm{N}, \mathrm{Ap} . \mathrm{S})\end{array}$ \\
\hline Khulna & $\begin{array}{l}-0.144(t=-4.78, \mathrm{NN}, \\
\mathrm{S})\end{array}$ & $-0.179(\mathrm{t}=-5.21, \mathrm{NN}, \mathrm{S})$ & $\begin{array}{l}-0.0633(\mathrm{t}=-1.37, \\
\text { Ap.N, S) }\end{array}$ & $\begin{array}{l}-0.160^{*}(\mathrm{t}=-4.44, \\
\text { Ap.N,S) }\end{array}$ \\
\hline Barisal & $\begin{array}{l}-0.0462(\mathrm{t}=-1.76, \mathrm{~N}, \\
\mathrm{NS})\end{array}$ & $\begin{array}{l}-0.0531 *(\mathrm{t}=-2.08, \\
\text { Ap.N,S) }\end{array}$ & $\begin{array}{l}+0.0300(\mathrm{t}=0.65, \text { Ap. } \mathrm{N}, \\
\mathrm{S})\end{array}$ & $\begin{array}{l}-0.0943(t=-2.27, \\
N, N S)\end{array}$ \\
\hline Sylhet & $\begin{array}{l}-0.0181(t=-0.69, \\
N, S)\end{array}$ & $\begin{array}{l}-0.0968(\mathrm{t}=-2.62, \\
\mathrm{NN}, \mathrm{S})\end{array}$ & $+0.0550(\mathrm{t}=1.33, \mathrm{~N}, \mathrm{~S})$ & $\begin{array}{l}+0.0233(\mathrm{t}=0.68 \text {, } \\
\text { Ap.N,S) }\end{array}$ \\
\hline Chittagong & $\begin{array}{l}-0.0108(\mathrm{t}=-0.43, \\
\mathrm{N}, \mathrm{S})\end{array}$ & $\begin{array}{l}-0.0381(t=-0.98, \\
N N, S)\end{array}$ & $-0.0284(\mathrm{t}=-0.61 \mathrm{~N}, \mathrm{~S})$ & $\begin{array}{l}+0.0362(\mathrm{t}=1.31, \\
\mathrm{N}, \mathrm{S})\end{array}$ \\
\hline
\end{tabular}

\section{Annual and Seasonal MXRH}

Table 5 presents the rates obtained from LT for Annual and Seasonal MXRH and Residual's Stationarity and Normality. The rate of annual MXRH was negative for Dhaka (- 0.047*) and Chittagong $\left(-0.0225^{*}\right)$ while for other stations it was positive. Significant positive rate was for Rajshahi $(0.016 *)$ and Barisal $(0.034 *)$ station only. The fairly high rates were for Khulna (0.020) and Sylhet (0.038) where the residuals follow nononormality.

During Kharif season, the rates of MXRH were negative for Dhaka (- 0.0435), Rajshahi (- 0.0058) and Chittagong (- 0.016) while it was positive for Khulna (0.0146), Barisal (0.024) and Sylhet (0.0097) The rates were fairly high but nononormality and/or nonstationarity were in the residuals.

During Prekharif season, the significant negative growth rates of MXRH were for Dhaka (- 0.060*) and Chittagong $\left(-0.028^{*}\right)$ while the significant positive growth rates of MXRH were for Rajshahi $(0.040 *)$ and Sylhet $(0.032 *)$. The rates for Khulna (+ $0.013)$ and Barisal (0.033) were fairly high but the residuals were nononormal and/or nonstationary.

During Rabi season, the high negative rate of MXRH was for Dhaka (- 0.045) where the residuals show nonstationarity but significant negative rate was for Chittagong $\left(-0.025^{*}\right)$. On the other hand, the rates were positive for other regions where the significant positive rate was for Rajshahi $(0.026 *)$. The growth rates for Khulna (0.033), Barisal (0.046) and Sylhet (0.077) were high but their residuals were not normal.
The growth rates of seasonal MXRH were negative in all the three seasons for Dhaka and Chittagong and positive in all the three seasons for Khulna, Barisal and Sylhet. For Rajshahi, it was negative during Kharif season but positive in Prekharif and Rabi season.

\section{Annual and Seasonal RNRH}

Table 6 presents the rates obtained from LT for Annual and Seasonal range relative humidity (RNRH) and Residual's Stationarity and Normality. The rate of growth of annual RNRH was negative for Dhaka (- 0.0598) and Chittagong (- 0.0117) whereas for other regions it was positive. The significant positive growth rate was for Khulna $(0.162 *)$ and Sylhet $\left(0.0569^{*}\right)$ only.

During Kharif season, the growth rates of RNRH were positive in all the six stations. The relatively higher rate was for Dhaka (0.0546), Khulna (0.190), Barisal $(0.0774 *)$ and Sylhet (0.0546) while the lower rate was for Rajshahi (0.0295) and Chittagong (0.0219).

During Prekharif season, the fairly high positive rates of RNRH were for Khulna (0.0763) and very low positive rate was for Barisal (0.0037) while for other regions the rates were negative where the significant negative rate was for Dhaka $\left(-0.205^{*}\right)$ only.

During Rabi season, high negative rate of RNRH was for Dhaka (- 0.093) where the residuals show nonstationarity but significant negative rate was for Chittagong $(-0.062 *)$. On the other hand, the rates were positive for other regions where significant positive rates were for Rajshahi $(0.182 *)$ and Khulna 
$(0.191 *)$. The higher positive rates were for Barisal $(0.141)$ and Sylhet $(0.053)$ too.

The growth rates of seasonal RNRH were positive during Kharif season and negative during Prekharif and Rabi season for Dhaka and Chittagong while the rates were positive during Kharif and Rabi season and negative during Prekharif season for Rajshahi and Sylhet. The rates were positive in all the six stations for Khulna and Barisal.

Table 5 Rate Obtained from LT for Annual and Seasonal MXRH and Residual's Stationarity and Normality

\begin{tabular}{|c|c|c|c|c|}
\hline Station & Annual & Kharif & Prekharif & Rabi \\
\hline Dhaka & $\begin{array}{l}-0.047 *(t=-7.72 \\
\text { Ap.N,S })\end{array}$ & $\begin{array}{l}-0.0435(\mathrm{t}=-6.72 \\
\text { Ap.N,NS) }\end{array}$ & $-0.060 *(\mathrm{t}=-6.03, \mathrm{~N}, \mathrm{~S})$ & $-0.045(\mathrm{t}=-5.69, \mathrm{~N}, \mathrm{NS})$ \\
\hline Rajshahi & $\begin{array}{l}+0.016 *(\mathrm{t}=2.84, \\
\mathrm{N}, \mathrm{S})\end{array}$ & $\begin{array}{l}-0.0058(\mathrm{t}=-1.22, \mathrm{NN}, \\
\mathrm{S})\end{array}$ & $+0.040 *(\mathrm{t}=2.57, \mathrm{Ap} . \mathrm{N}, \mathrm{S})$ & $\begin{array}{l}+0.026^{*}(t=3.25 \\
\text { Ap.N,Ap S })\end{array}$ \\
\hline Khulna & $\begin{array}{l}+0.020 \\
(\mathrm{t}=3.68, \mathrm{NN}, \mathrm{S})\end{array}$ & $+0.0146(\mathrm{t}=1.49, \mathrm{NN}, \mathrm{S}$ & $+0.013(\mathrm{t}=1.81, \mathrm{NN}, \mathrm{S})$ & $+0.033(\mathrm{t}=5.19, \mathrm{NN}, \mathrm{S})$ \\
\hline Barisal & $\begin{array}{l}+0.034 *(t=6.26, \\
\text { Ap.N,S })\end{array}$ & $\begin{array}{l}+0.024(\mathrm{t}=5.88, \mathrm{NN}, \mathrm{S} \\
\text { ) }\end{array}$ & $+0.033(\mathrm{t}=5.53, \mathrm{~N}, \mathrm{~S})$ & $\begin{array}{l}+0.046(t=5.31, N N, S \\
)\end{array}$ \\
\hline Sylhet & $\begin{array}{l}+0.038(\mathrm{t}=4.18 \\
\mathrm{NN}, \mathrm{S})\end{array}$ & $\begin{array}{l}+0.0097(\mathrm{t}=2.03, \\
\text { Ap.N,NS ) }\end{array}$ & $\begin{array}{l}+0.032 *(\mathrm{t}=3.6 \\
\text { Ap.N,Ap.S })\end{array}$ & $+0.077(\mathrm{t}=3, \mathrm{NN}, \mathrm{S})$ \\
\hline $\begin{array}{l}\text { Chittagon } \\
\text { g }\end{array}$ & $\begin{array}{l}-0.0225^{*}(\mathrm{t}=- \\
\text { 5.11,Ap.N,S })\end{array}$ & $-0.016(\mathrm{t}=-3.81, \mathrm{NN}, \mathrm{S})$ & $\begin{array}{l}-0.028 *(\mathrm{t}=-4.24, \text { Ap. } \mathrm{N} \\
\mathrm{S})\end{array}$ & $\begin{array}{l}-0.025^{*}(\mathrm{t}=-3.6, \text { Ap.N, } \\
\mathrm{S})\end{array}$ \\
\hline
\end{tabular}

Table 6. Rates obtained from LT for Annual and Seasonal RNRH and Residual's Stationarity and Normality

\begin{tabular}{|c|c|c|c|c|}
\hline Station & Annual & Kharif & Prekharif & Rabi \\
\hline Dhaka & $\begin{array}{l}-0.0598(\mathrm{t}=-2.36 \\
\text { Ap.N NS) }\end{array}$ & $+0.0546(\mathrm{t}=1.89, \mathrm{~N}, \mathrm{~S})$ & $-0.205^{*}(\mathrm{t}=-4.3, \mathrm{~N}$, Ap. $\mathrm{S})$ & $-0.093(\mathrm{t}=-3.29, \mathrm{~N}, \mathrm{NS})$ \\
\hline Rajshahi & $\begin{array}{l}+0.0716(t=1.56, \\
\text { Ap.N,S })\end{array}$ & $\begin{array}{l}+0.0295(\mathrm{t}=0.38, \mathrm{NN}, \\
\mathrm{S})\end{array}$ & $-0.0038(\mathrm{t}=-0.06, \mathrm{~N}, \mathrm{~S})$ & $\begin{array}{l}+0.182 *(\mathrm{t}=3.31, \mathrm{~N}, \\
\text { Ap.S })\end{array}$ \\
\hline Khulna & $\begin{array}{l}+0.162 *(t=5.22 \\
\text { Ap.N, } S)\end{array}$ & $+0.190(\mathrm{t}=5.6, \mathrm{NN}, \mathrm{S})$ & $+0.0763(\mathrm{t}=1.64, \mathrm{~N}, \mathrm{~S})$ & $+0.191 *(\mathrm{t}=5.24, \mathrm{~N}, \mathrm{~S})$ \\
\hline Barisal & $\begin{array}{l}+0.0802(t=2.72, \\
\text { Ap. N,NS })\end{array}$ & $\begin{array}{l}+0.0774 *(t=2.91, \\
\text { Ap.N,S })\end{array}$ & $+0.0037(\mathrm{t}=0.08, \mathrm{~N}, \mathrm{~S})$ & $\begin{array}{l}+0.141(\mathrm{t}=3.01, \text { Ap.N, } \\
\text { NS) }\end{array}$ \\
\hline Sylhet & $\begin{array}{l}+0.0569 *(\mathrm{t}=2.01, \\
\text { Ap.N, S) }\end{array}$ & $\begin{array}{l}+0.106(\mathrm{t}=2.83, \mathrm{NN}, \\
\mathrm{S})\end{array}$ & $-0.023(\mathrm{t}=-0.57, \mathrm{Ap} . \mathrm{N}, \mathrm{S})$ & $\begin{array}{l}+0.053(\mathrm{t}=1.33, \mathrm{~N}, \\
\text { Ap.S) }\end{array}$ \\
\hline Chittagong & $\begin{array}{l}-0.0117(\mathrm{t}=-0.45 \\
\mathrm{N}, \mathrm{S})\end{array}$ & $\begin{array}{l}+0.0219(\mathrm{t}=-0.56, \mathrm{NN}, \\
\mathrm{S})\end{array}$ & $\begin{array}{l}-0.00007(\mathrm{t}=-0.00, \mathrm{NN}, \\
\mathrm{S})\end{array}$ & $-0.062 *(\mathrm{t}=-2.04, \mathrm{~N}, \mathrm{~S})$ \\
\hline
\end{tabular}

\section{Model Fitting and Forecasting}

An attempt was made to fit the univariate BoxJenkin's ARIMA model to forecast the monthly ARH data for January 2009-December 2012. The diagnostic techniques such as histogram of residuals, normal probability plot of residuals and ACF and PACF display of residuals TS plots for residual versus fitted values and TS plots for residual versus order of the data were used for checking residuals of
ARIMA models. Estimated ARIMA models are presented in Table 7. The data for February 1956 (10) of ARH in Khulna was detected as outlier and it was replaced by the estimated ARH (67.62) obtained from the fitted ARIMA model for 1957 to 2008 where the training set was considered for 1959-2008 (Table 8). The ACF displays for residual autocorrelations for the estimated models were fairly small relative to their standard errors for all the variables. The histograms 
of the residuals were symmetrical suggesting that the shocks may be normally or approximately normally distributed. The normal probability plots of the residuals did not deviate badly from straight lines (fairly close to a straight line), again suggesting that the shocks were normal. Point and interval forecasts of monthly ARH were presented in Table 9. Some TS plots of point and interval forecasts for monthly ARH and some residual plots are shown in the Fig. 1.

Table 7. Results of Estimated ARIMA Models for Monthly ARH for Six Stations

\begin{tabular}{|c|c|c|c|c|c|c|}
\hline Station & Model & Equation of Model & MRMSFE & SS & DF & MS \\
\hline Dhaka & $\operatorname{ARIMA}(1,0,0)(0,1,1)_{12}$ & $\begin{array}{c}(1-0.2965 \mathrm{~B}) \nabla_{12} \mathrm{y}_{\mathrm{t}}=-0.03574+(1- \\
\left.0.9473 \mathrm{~B}^{12}\right) \varepsilon_{\mathrm{t}} \\
\text { se of coeff. }(0.0378)(0.008584)(0.0154)\end{array}$ & 3.830 & 6290.28 & 657 & 9.57 \\
\hline Rajshahi & $\operatorname{ARIMA}(1,0,1)(1,1,1)_{12}$ & $\begin{array}{c}(1-0.3525 \mathrm{~B})(1+0.0025) \nabla_{12} \mathrm{y}_{\mathrm{t}}=0.10266 \\
+(1+0.0644 \mathrm{~B})\left(1-0.9481 \mathrm{~B}^{12}\right) \varepsilon_{\mathrm{t}} \\
\text { se of coeff }(0.1008)(0.0467)(0.01326)( \\
0.1074)(0.0193)\end{array}$ & 3.630 & 7798.88 & 523 & 14.91 \\
\hline Khulna & $\operatorname{ARIMA}(1,0,1)(0,1,1)_{12}$ & $\begin{array}{c}(1-0.6171 \mathrm{~B}) \nabla_{12} \quad \mathrm{y}_{\mathrm{t}}=0.019964+(1- \\
0.1593 \mathrm{~B})\left(1-0.9509 \mathrm{~B}^{12}\right) \varepsilon_{\mathrm{t}} \\
\text { se of coeff. }(0.058)(0.006973)( \\
0.0727)(0.0145)\end{array}$ & 2.942 & 8515.39 & 716 & 11.89 \\
\hline Barisal & $\begin{array}{c}\operatorname{ARIMA}(1,0,0)(1,1,1) \\
12\end{array}$ & $\begin{array}{c}(1-0.4877 \mathrm{~B})\left(1-0.0106 \mathrm{~B}^{12}\right) \nabla_{12} \mathrm{y}_{\mathrm{t}}= \\
0.049891+\left(1-0.9596 \mathrm{~B}^{12}\right) \varepsilon_{\mathrm{t}} \\
\text { se of coeff. }(0.0336)(0.0393)( \\
0.005897)(0.0147)\end{array}$ & 2.707 & 5030.43 & 704 & 7.15 \\
\hline Sylhet & $\begin{array}{c}\operatorname{ARIMA}(1,0,0)(0,1,1) \\
12\end{array}$ & $\begin{array}{c}(1-0.3264 \mathrm{~B}) \nabla_{12} \mathrm{y}_{\mathrm{t}}=0.01166+(1- \\
\left.0.9502 \mathrm{~B}^{12}\right) \varepsilon_{\mathrm{t}} \\
\text { se of coeff. }(0.0383)( \\
0.009238)(0.0152)\end{array}$ & 3.479 & 6894.33 & 621 & 11.10 \\
\hline Chittagong & $\begin{array}{c}\operatorname{ARIMA}(2,0,0)(1,1,1) \\
12\end{array}$ & $\begin{array}{c}(1-0.3241 \mathrm{~B})\left(1-0.153 \mathrm{~B}^{2}\right)(1- \\
\left.0.0378 \mathrm{~B}^{12}\right) \nabla_{12} \mathrm{y}_{\mathrm{t}}=-0.01188+(1- \\
\left.0.963 \mathrm{~B}^{12}\right) \varepsilon_{\mathrm{t}} \\
\text { se of coeff. }(0.038)(0.0377)(0.04) \\
0.005788)(0.014)\end{array}$ & 3.625 & 5229.27 & 703 & 7.44 \\
\hline
\end{tabular}

** SQ R T = Square root transformed, MRMSFE = Minimum root mean square forecasting error, MS = Mean square error, se of coeff. $=$ Standard error of coefficient

Table 8. ARIMA Models for Monthly ARH in Sylhet

\begin{tabular}{|c|c|c|c|c|c|c|}
\hline Station & Model & Equation of Model & MRMSFE & SS & DF & MS \\
\hline $\begin{array}{c}\text { Sylhet } \\
\text { (1957- } \\
\text { 2008) }\end{array}$ & $\begin{array}{c}\operatorname{ARIMA}(1,1,1)(1,1,1) \\
12\end{array}$ & $\begin{array}{c}(1-0.2355 \mathrm{~B})\left(1+0.0527 \mathrm{~B}^{12}\right) \nabla_{12} \mathrm{y}_{\mathrm{t}}= \\
0.000881+(1-0.9428 \mathrm{~B})\left(1-0.9059 \mathrm{~B}^{12}\right) \varepsilon_{\mathrm{t}} \\
\text { se of coeff. }(0.0479)(0.0510)(0.001021) \\
(0.0174) \\
(0.0222)\end{array}$ & 4.014 & 5564.03 & 486 & 11.45 \\
\hline
\end{tabular}


Table 9. Point and Interval Forecasts for Monthly ARH

\begin{tabular}{|c|c|c|c|c|c|c|c|c|c|c|c|c|c|c|c|c|c|c|}
\hline \multirow[t]{2}{*}{ Period } & \multicolumn{3}{|c|}{ Dhaka for 2009} & \multicolumn{3}{|c|}{ Rajshahi for 2009} & \multicolumn{3}{|c|}{ Khulna for 2009} & \multicolumn{3}{|c|}{ Barisal for 2009} & \multicolumn{3}{|c|}{ Chittagong for 2009} & \multicolumn{3}{|c|}{ Sylhet for 2009} \\
\hline & PE & $\mathbf{I E}(\mathbf{L})$ & IE(U) & PE & IE(L) & IE(U) & PE & IE(L) & IE(U) & PE & IE(L) & IE(U) & PE & IE(L) & IE(U) & PE & IE(L) & IE(U) \\
\hline January & 71.3 & 65.2 & 77.4 & 81.0 & 73.4 & 88.5 & 79.5 & 72.7 & 86.2 & 82.8 & 77.6 & 88.1 & 75.9 & 70.6 & 81.3 & 75.8 & 69.3 & 82.4 \\
\hline February & 3.4 & 57.0 & 69.7 & 73.4 & 65.2 & 81.6 & 75.3 & 67.9 & 82.8 & 78.7 & 72.9 & 4.5 & 72.4 & 66.8 & 78.1 & 68.6 & 51.7 & 75.5 \\
\hline March & 0.7 & 54.4 & 67.1 & 64.5 & 56.2 & 72.8 & 73.1 & 5.4 & 80.8 & 76.7 & 70.7 & 82.6 & 74.1 & 8.4 & 79.9 & 67.0 & 0.1 & 73.9 \\
\hline April & 8.9 & 6 & 75.2 & 67.2 & 59.0 & 75.5 & 76.6 & 68.9 & 84.4 & 81.0 & 75.0 & 87.0 & 77.2 & 71.4 & 3.1 & 75.2 & 8.3 & 82.1 \\
\hline May & 74.9 & 68.5 & 81.2 & 76.5 & 68.2 & 84.8 & 79.5 & 71.7 & 87.3 & 83.9 & 77.9 & 89.9 & 79.3 & 73.5 & 85.1 & 80.8 & 73.9 & 87.7 \\
\hline June & 81.4 & 75.1 & 87.8 & 85.3 & 77.0 & 93.6 & 86.0 & 78.2 & 93.8 & 89.5 & 83.5 & 95.5 & 84.0 & 78.2 & 89.9 & 86.8 & 79.9 & 93.7 \\
\hline July & 82.7 & 76.3 & 89.0 & 89.4 & 81.1 & 97.7 & 88.3 & 80.4 & 96.1 & 91.1 & 85.1 & 97.1 & 85.6 & 79.8 & 91.5 & 87.2 & 80.3 & 94.1 \\
\hline Augus & 81.4 & 75.0 & 87.7 & 88.4 & 80.1 & 96.7 & 87.1 & 79.3 & 95.0 & 90.4 & 84.4 & 96.4 & 84.8 & 78.9 & 90.7 & 86.1 & 79.2 & 93.0 \\
\hline Sept & 81.8 & 75.4 & 88.1 & 88.1 & 79.8 & 96.4 & 87.3 & 79.5 & 95.1 & 90.0 & 84.0 & 96.0 & 83.3 & 77.4 & 89.1 & 85.7 & 78.8 & 92.6 \\
\hline Octo & 77.8 & 71.5 & 84.2 & 84.9 & 76.6 & 93.2 & 84.5 & 76.7 & 92.3 & 88.0 & 82.0 & 94.0 & 81.7 & 75.8 & 87.5 & 82.7 & 75.8 & 89.6 \\
\hline & 72.2 & 65.8 & 78.5 & 80.4 & 72.1 & 88.7 & 79.8 & 72.0 & 87.7 & 84.4 & 78.4 & 90.4 & 77.5 & 71.7 & 83 & 76.8 & 69.9 & 83.7 \\
\hline December & 71.6 & 65.2 & 77.9 & 79.6 & 71.3 & 87.9 & 78.5 & 70.7 & 86.4 & 82.9 & 76.9 & 88.9 & 75.4 & 69.5 & 81.2 & 74.6 & 67.7 & 81.5 \\
\hline
\end{tabular}

Table 9. continued

\begin{tabular}{|c|c|c|c|c|c|c|c|c|c|c|c|c|c|c|c|c|c|c|}
\hline \multirow[t]{2}{*}{ Period } & \multicolumn{3}{|c|}{ Dhaka for 2010} & \multicolumn{3}{|c|}{ Rajshahi for 2010} & \multicolumn{3}{|c|}{ Khulna for 2010} & \multicolumn{3}{|c|}{ Barisal for 2010} & \multicolumn{3}{|c|}{ Chittagong for 2010} & \multicolumn{3}{|c|}{ Sylhet for 2010} \\
\hline & $\mathbf{P E}$ & IE(L) & IE(U) & $\mathbf{P E}$ & IE(L) & IE(U) & $\mathbf{P E}$ & IE(L) & IE(U) & PE & IE(L) & IE(U) & $\mathbf{P E}$ & IE(L) & IE(U) & $\mathbf{P E}$ & IE(L) & IE(U) \\
\hline January & 69.0 & 62.7 & 75.4 & 78.8 & 70.5 & 87.1 & 77.1 & 69.3 & 85.0 & 81.3 & 75.3 & 87.4 & 72.7 & 66.8 & 78.5 & 74.4 & 67.5 & 81.3 \\
\hline February & 62.7 & 56.3 & 69.0 & 72.7 & 64.4 & 81.0 & 73.9 & 66.1 & 81.8 & 78.1 & 72.0 & 84.1 & 70.1 & 64.3 & 76.0 & 68.2 & 61.2 & 75.1 \\
\hline March & 60.5 & 54.1 & 66.8 & 64.4 & 56.1 & 72.7 & 72.2 & 64.4 & 80.1 & 76.4 & 70.4 & 82.4 & 72.7 & 66.8 & 78.5 & 66.9 & 60.0 & 73.8 \\
\hline April & 68.8 & 62.4 & 75.1 & 67.3 & 59.0 & 75.6 & 76.1 & 68.3 & 84.0 & 81.0 & 75.0 & 87.0 & 76.6 & 70.7 & 82.4 & 75.2 & 68.3 & 82.1 \\
\hline May & 74.8 & 68.4 & 81.2 & 76.6 & 68.4 & 84.9 & 79.2 & 71.3 & 87.0 & 84.0 & 78.0 & 90.0 & 78.9 & 73.0 & 84.8 & 80.8 & 73.9 & 87.7 \\
\hline June & 81.4 & 75.0 & 87.8 & 85.4 & 77.1 & 93.7 & 85.8 & 78.0 & 93.7 & 89.6 & 83.6 & 95.6 & 83.8 & 77.9 & 89.7 & 86.8 & 79.9 & 93.8 \\
\hline July & 2.6 & 76.3 & 89.0 & 89.6 & 81.3 & 97.8 & 88.2 & 80.4 & 96.0 & 91.2 & 85.2 & 97.2 & 85.4 & 79.5 & 91.3 & 87.2 & 80.3 & 94.2 \\
\hline August & 81.3 & 74.9 & 87.7 & 88.6 & 80.3 & 96.9 & 87.1 & 79.3 & 94.9 & 90.5 & 84.5 & 96.5 & 84.6 & 78.8 & 90.5 & 86.1 & 79.2 & 93.0 \\
\hline September & 81.7 & 75.3 & 88.1 & 88.3 & 80.0 & 96.6 & 87.3 & 79.5 & 95.2 & 90.1 & 84.1 & 96.1 & 83.2 & 77.3 & 89.1 & 85.7 & 78.8 & 92.6 \\
\hline \begin{tabular}{|l|} 
October \\
\end{tabular} & 77.8 & 71.4 & 84.1 & 85.0 & 76.7 & 93.3 & 84.5 & 76.7 & 92.4 & 88.1 & 82.1 & 94.1 & 81.5 & 75.7 & 87.4 & 82.7 & 75.8 & 89.6 \\
\hline November & 72.1 & 65.7 & 78.5 & 80.5 & 72.2 & 88.8 & 79.9 & 72.0 & 87.7 & 84.5 & 78.5 & 90.5 & 77.4 & 71.5 & 83.3 & 76.8 & 69.9 & 83.7 \\
\hline December & 71.5 & 65.2 & 77.9 & 79.8 & 71.5 & 88.1 & 78.6 & 70.8 & 86.4 & 82.9 & 76.9 & 89.0 & 75.0 & 69.2 & 80.9 & 74.6 & 67.7 & 81.6 \\
\hline
\end{tabular}

Table 9. continued

\begin{tabular}{|c|c|c|c|c|c|c|c|c|c|c|c|c|c|c|c|c|c|c|}
\hline \multirow[t]{2}{*}{ Period } & \multicolumn{3}{|c|}{ Dhaka for 2011} & \multicolumn{3}{|c|}{ Rajshahi for 2011} & \multicolumn{3}{|c|}{ Khulna for 2011} & \multicolumn{3}{|c|}{ Barisal for 2011} & \multicolumn{3}{|c|}{ Chittagong for 2011} & \multicolumn{3}{|c|}{ Sylhet for 2011} \\
\hline & PE & IE(L) & $\operatorname{IE}(\mathbf{U})$ & PE & $\mathbf{I E}(\mathbf{L})$ & IE(U) & $\mathbf{P E}$ & IE(L) & $\mathbf{I E}(\mathbf{U})$ & PE & IE(L) & IE(U) & PE & IE(L) & $\operatorname{IE}(\mathbf{U})$ & PE & $\mathrm{IE}(\mathbf{L})$ & IE(U) \\
\hline & 69.0 & & 5.4 & & & 872 & & & Q5 & & & & & & & & & \begin{tabular}{|l|l}
81.4 \\
\end{tabular} \\
\hline & & & & & & & & & & & & & & & & & & \\
\hline & & & & & & & & & & & & & & & & & & \\
\hline & & & & & & & & & & & & & & & & & & 2.1 \\
\hline$[\varepsilon$ & & & & & & & & & & & & & & & & & & 37.7 \\
\hline & & & 87. & & & & & & & 9.7 & & & & & & & .9 & 3.8 \\
\hline $\mathbf{u}$ & & & 89.0 & 9.7 & & & 8.2 & & 96. & 91.3 & & 97.3 & 5.4 & & 1.2 & 37.3 & 0.3 & 94.2 \\
\hline & & & 87.6 & 37 & & & & & 05 & 90.6 & & 96.6 & 34.6 & & 0.5 & 36.1 & 9.2 & 93.1 \\
\hline & & & 88.0 & & & 96.7 & & & 95.2 & 90.2 & 2 & 96.2 & 3.2 & & 39.0 & 35.7 & 8.8 & 92.7 \\
\hline & & & 4.1 & & & & & & 92.4 & 88.2 & & 94.2 & & & 87. & 82.7 & 5.8 & 89.6 \\
\hline & 72.1 & & & 0.7 & & 89.0 & 79.9 & & 87.8 & 84.6 & & 90.6 & 77.4 & & 83.2 & 76.8 & 59.9 & 83.7 \\
\hline ecember & 71.5 & 65.1 & 77.8 & 79.9 & 71.6 & 88.2 & 78.6 & 70.8 & 86.5 & 83.0 & 77.0 & 89.1 & 75.0 & 69.1 & 80.9 & 74.7 & 67.7 & 81.6 \\
\hline
\end{tabular}

Table 9. continued

\begin{tabular}{|c|c|c|c|c|c|c|c|c|c|c|c|c|c|c|c|c|c|c|}
\hline \multirow{2}{*}{ Period } & \multicolumn{3}{|c|}{ Dhaka for 2012} & \multicolumn{3}{|c|}{ Rajshahi for 2012} & \multicolumn{3}{|c|}{ Khulna for 2012} & \multicolumn{3}{|c|}{ Barisal for 2012} & \multicolumn{3}{|c|}{ Chittagong for 2012} & \multicolumn{3}{|c|}{ Sylhet for 2012} \\
\hline & $\mathbf{P E}$ & IE(L) & IE(U) & $\mathbf{P E}$ & IE(L) & IE(U) & $\mathbf{P E}$ & IE(L) & IE(U) & $\mathbf{P E}$ & IE(L) & IE(U) & $\mathbf{P E}$ & IE(L) & IE(U) & $\mathbf{P E}$ & IE(L) & IE $(\mathbf{U})$ \\
\hline January & 68.9 & 62.6 & 75.3 & 79.1 & 70.8 & 87.4 & 77.2 & 69.4 & 85.1 & 81.5 & 75.5 & 87.5 & 72.5 & 66.6 & 78.4 & 74.5 & 67.5 & 81.4 \\
\hline February & 62.6 & 56.2 & 68.9 & 73.0 & 64.7 & 81.3 & 74.0 & 66.2 & 81.9 & 78.2 & 72.2 & 84.3 & 70.0 & 64.1 & 75.9 & 68.2 & 61.3 & 75.1 \\
\hline March & 60.4 & 54.0 & 66.8 & 64.7 & 56.4 & 73.0 & 72.3 & 64.5 & 80.2 & 76.6 & 70.6 & 82.6 & 72.6 & 66.7 & 78.4 & 66.9 & 60.0 & 73.9 \\
\hline April & 68.7 & 62.3 & 75.0 & 67.6 & 59.3 & 75.9 & 76.2 & 68.4 & 84.1 & 81.2 & 75.1 & 87.2 & 76.5 & 70.6 & 82.4 & 75.2 & 68.3 & 82.2 \\
\hline May & 74.7 & 68.3 & 81.1 & 77.0 & 68.6 & 85.3 & 79.3 & 71.4 & 87.1 & 84.2 & 78.1 & 90.2 & 78.8 & 72.9 & 84.7 & 80.8 & 73.9 & 87.8 \\
\hline June & 81.3 & 74.9 & 87.7 & 85.7 & 77.4 & 94.1 & 86.0 & 78.1 & 93.8 & 89.8 & 83.8 & 95.8 & 83.7 & 77.9 & 89.6 & 86.9 & 79.9 & 93.8 \\
\hline July & 82.5 & 76.2 & 88.9 & 89.9 & 81.5 & 98.2 & 88.3 & 80.4 & 96.1 & 91.4 & 85.4 & 97.4 & 85.3 & 79.5 & 91.2 & 87.3 & 80.3 & 94.2 \\
\hline August & 81.2 & 74.8 & 87.6 & 88.9 & 80.6 & 97.2 & 87.2 & 79.4 & 95.1 & 90.7 & 84.7 & 96.7 & 84.6 & 78.7 & 90.5 & 86.1 & 79.2 & 93.1 \\
\hline September & 81.6 & 75.2 & 88.0 & 88.6 & 80.3 & 96.9 & 87.4 & 79.6 & 95.3 & 90.3 & 84.3 & 96.3 & 83.1 & 77.3 & 89.0 & 85.8 & 78.8 & 92.7 \\
\hline October & 77.7 & 71.3 & 84.1 & 85.3 & 77.0 & 93.7 & 84.6 & 76.8 & 92.5 & 88.3 & 82.3 & 94.4 & 81.5 & 75.6 & 87.4 & 82.7 & 75.8 & 89.7 \\
\hline November & 72.0 & 65.6 & 78.4 & 80.8 & 72.5 & 89.2 & 80.0 & 72.1 & 87.8 & 84.7 & 78.7 & 90.7 & 77.3 & 71.5 & 83.2 & 76.8 & 69.9 & 83.8 \\
\hline December & 71.4 & 65.0 & 77.8 & 80.1 & 71.8 & 88.4 & 78.7 & 70.8 & 86.5 & 83.1 & 77.1 & 89.2 & 75.0 & 69.1 & 80.8 & 74.7 & 67.7 & 81.6 \\
\hline
\end{tabular}


Normal Probability Plot of the Residuals (response is C31)

a

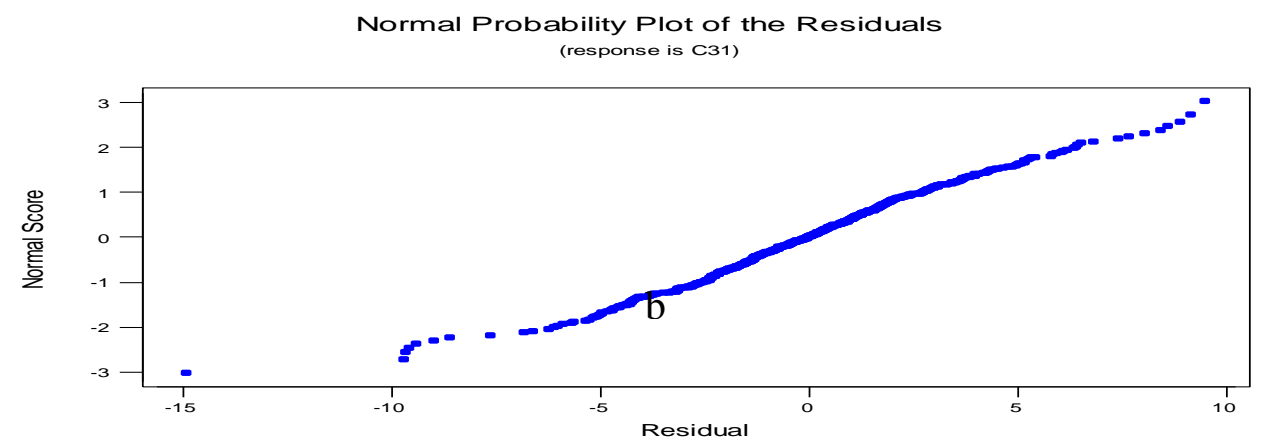

ACF of Residuals for $\mathrm{C} 31$

(with 95\% confidence limits for the autocorrelations)

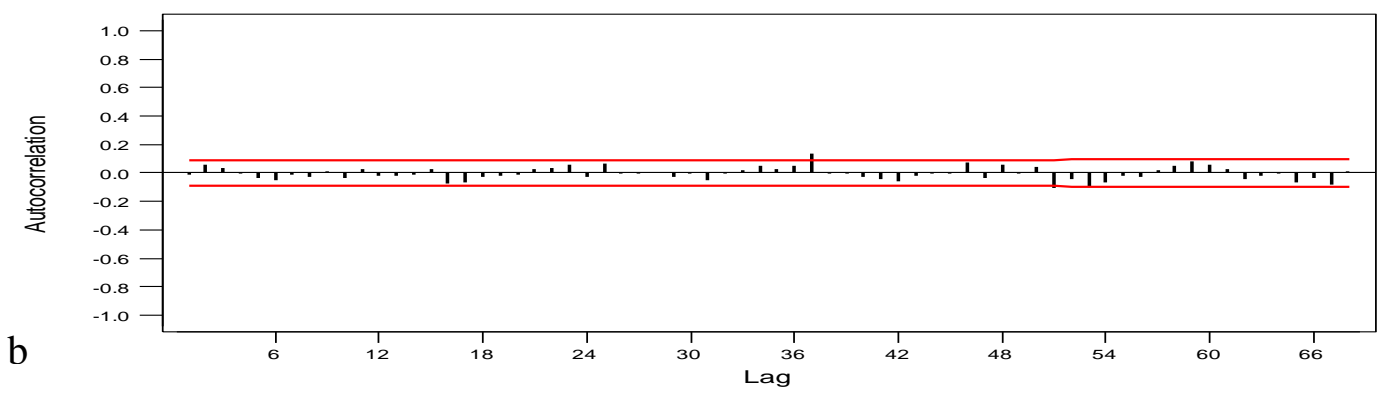

Time Series Plot for $\mathrm{C} 31$

(with forecasts and their 95\% confidence limits)

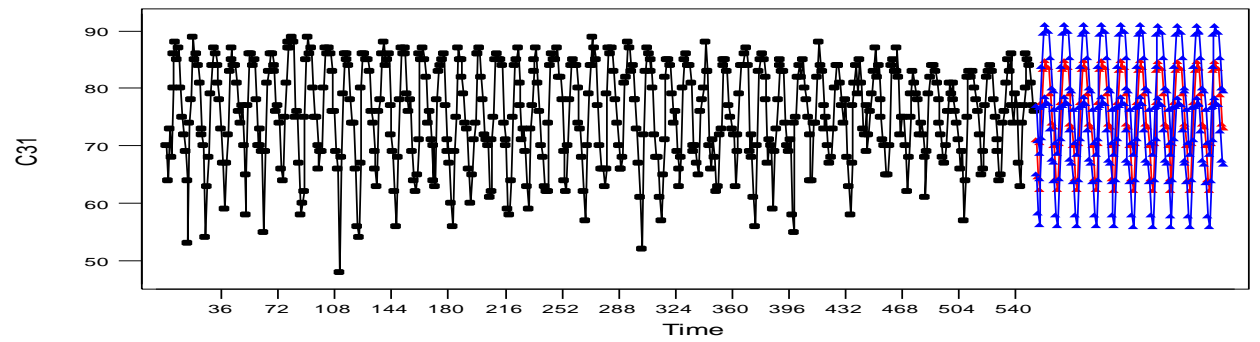

(with forecasts and their $95 \%$ confidence limits)

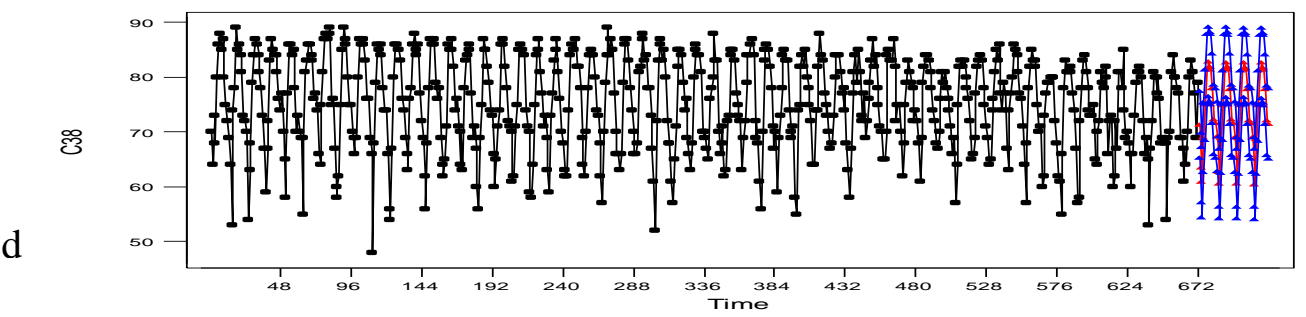

Fig.1. (a) NP plot for residuals of Dhaka ARH (b) ACF of residuals for Dhaka ARH (c) Forecasted ARH during 1999-2008 for Dhaka (d) Forecasted (Red line - Indication of point estimate and blue line - Indication of 95\% confidence interval) ARH during 2009-2012 for Dhaka 


\section{Conclusions}

The foregoing analyses indicated that the rates of growth of annual ARH were negative for Dhaka and Chittagong while positive for the rest four stations. The growth rates of $\mathrm{CV}$ of annual ARH were negative for all the six stations. The rate of growth of seasonal ARH was negative for Dhaka and positive for Rajshahi and Barisal in all the three seasons. It was negative during Kharif season and positive in Prekharif and Rabi season for Khulna and Sylhet. It was negative during Kharif and Prekharif season and positive in Rabi season for Chittagong.

The rate of growth of annual MNRH was positive for Dhaka while for other stations negative. The rate of growth of MNRH was negative during Kharif season and positive during Prekharif and Rabi season for Dhaka and Sylhet. It was negative during Kharif and Rabi season and positive in Prekharif season for Rajshahi and Barisal. It was negative during Kharif and Prekharif season but positive in Rabi season for Chittagong and it was negative in all the three seasons for Khulna.

The rate of growth of annual MXRH was negative for Dhaka and Chittagong while for other stations it was positive. The growth rates of seasonal MXRH were negative in all the three seasons for Dhaka and Chittagong and positive in all the three seasons for Khulna, Barisal and Sylhet. For Rajshahi, it was negative during Kharif season but positive in Prekharif and Rabi season.

The rates for annual RNRH were negative for Dhaka and Chittagong while for other regions those were positive. The growth rate for seasonal RNRH were positive during Kharif season and negative during Prekharif and Rabi season for Dhaka and Chittagong while the rates were positive during Kharif and Rabi season and negative during Prekharif season for Rajshahi and Sylhet. The rates were positive in all the six stations for Khulna and Barisal.

The fitted model for monthly ARH of Dhaka, Rajshahi, Khulna, Barisal, Sylhet and Chittagong are $\operatorname{ARIMA}(1,0,0)(0,1,1)_{12}, \quad \operatorname{ARIMA}(1,0,1)(1,1,1)_{12}$, $\operatorname{ARIMA}(1,0,1)(0,1,1)_{12}, \quad \operatorname{ARIMA}(1,0,0)(1,1,1)_{12}$, $\operatorname{ARIMA}(1,0,0)(0,1,1)_{12}$ and $\operatorname{ARIMA}(2,0,0)(1,1,1)_{12}$, respectively on the basis of minimum root mean square forecasting error.

The findings have shown that the climate of this country has been changing in terms of average, minimum, maximum and range relative humidity. This may affect on agricultural production. So, the scientists should set their plan of work keeping the changing pattern of atmospheric relative humidity of this country - a vital element of the climate.

\section{References}

Box, G. E. P. and Jenkins, G. M. 1976.Time Series Analysis: Forecasting and Control, Prentince Hall, Inc.575p.

Lenka, D. 1998. Climate, Weather and Crops in India. New Delhi, India.

Pankraiz, A. 1991. Forecasting with Dynamic Regression Models. John Wiley \& Sons Inc. New York. 